\title{
Should Scientific Realists Embrace Theoretical Conservatism?
}

[Penultimate draft; forthcoming in Studies in History and Philosophy of Science]

Finnur Dellsén

\begin{abstract}
A prominent type of scientific realism holds that some important parts of our best current scientific theories are at least approximately true. According to such realists, radically distinct alternatives to these theories or theory-parts are unlikely to be approximately true. Thus one might be tempted to argue, as the prominent anti-realist Kyle Stanford recently did, that realists of this kind have little or no reason to encourage scientists to attempt to identify and develop theoretical alternatives that are radically distinct from currently accepted theories in the relevant respects. In other words, it may seem that realists should recommend that scientists be relatively conservative in their theoretical endeavors. This paper aims to show that this argument is mistaken. While realists should indeed be less optimistic of finding radically distinct alternatives to replace current theories, realists also have greater reasons to value the outcomes of such searches. Interestingly, this holds both for successful and failed attempts to identify and develop such alternatives.
\end{abstract}

Keywords: theoretical conservatism; scientific realism; unconceived alternatives; radical theory change.

\section{Introduction}

A number of science policy commentators have recently expressed the concern that scientific research is becoming increasingly conservative. Specifically, it is claimed that contemporary scientists are being steered towards 'safe' research that builds upon, and thus assumes, large parts of previous science; accordingly, new scientific research is becoming less likely to disrupt 
existing scientific paradigms. ${ }^{1}$ Agencies like the National Science Foundation (NSF) and the European Research Council (ERC) have reacted to this perceived increase of conservative science by establishing practices and guidelines to ensure that 'high-risk/high-gain' and 'transformative' science is being funded, even by the largest and most prestigious grant schemes. Interestingly, then, these agencies view the trend towards conservatism in science not only as a fact, but as something that should be counteracted - even if that means risking that funding agencies occasionally end up funding infertile or misguided research.

But are the NSF and ERC correct in thinking that increasing conservatism is something to worry about? Stanford (2015b: 873-875; see also 2006: 209) has recently argued that how one answers this question should depend on one's stance in the perennial debate between scientific realists and anti-realists. ${ }^{2}$ In so far as scientific realists believe that some specific parts of current best theories are probably at least approximately true, they should be happy to rule out of consideration lines of research that are fundamentally at odds with their realist beliefs. Hence scientific realists "can afford to be cavalier or even enthusiastic about evidence of increasing theoretical conservativeness in science" (2015: 873-4). By contrast, in so far as anti-realists believe that current science is far from settled, they have reason to think that attempts to identify and develop serious theoretical alternatives to current scientific orthodoxy are likely - or at least likelier - to be successful. Thus, argues Stanford, anti-realists will view the anti-conservative search for new and radically different theoretical paradigms as a more important part of the scientific enterprise than their realist opponents. As Stanford emphasizes, this would mean that the debate over realism and anti-realism has real-life practical implications for the manner in which science should be carried out. It "actually makes a difference to how we should go about pursuing scientific inquiry itself" (2015b: 878).

Although Stanford himself does not discuss specific parts of contemporary science in which the realism debate would make a difference in this way, it may be helpful to consider a concrete case for illustration. If general relativity is the correct theory of gravity on large scales, then cosmological data regarding the structure of the universe is only explicable by assuming that around $27 \%$ of the universe's total mass-energy be an invisible form of matter, dark matter. Specifically, the existence of this amount of dark matter is posited by the best

\footnotetext{
${ }^{1}$ See Stanford (2015c), and references therein.

${ }^{2}$ In section 2, I characterize the realism debate with more nuance than I can do in this introduction.
} 
current cosmological model of the universe, the so-called concordance model, which in turn assumes general relativity to be correct on large scales. This model is widely accepted by astrophysicists (often referred to as the 'standard model' of cosmology) and has been enormously successful in recent years - correctly predicting a number of distinct phenomena such as the rotation curves of galaxies, the large-scale structure of the universe, the virial discrepancy (i.e. the ratio of dynamical to observable mass), and recently obtained data of the cosmic microwave background from the Planck space observatory. ${ }^{3}$

Given the empirical success of the cosmological model in which dark matter plays an essential role, many self-proclaimed realists (though certainly not all) ${ }^{4}$ will take the existence of dark matter as probably at least approximately correct. According to such realists about dark matter, we might later change the details of our conception of dark matter in various ways (e.g. in whether we end up taking it as completely 'dark', or instead as directly detectible in some currently unknown manner). But by these realists' lights, some important part of our conception of dark matter will probably be retained within future physical theory, i.e. in future theories where the concordance model has been supplemented or even replaced by a very different model, e.g. one that does not assume general relativity to hold on large scales. By contrast, an anti-realist about dark matter will find it less likely that any form of dark matter will be retained in future physical theory, because by her lights it is more likely that future theories (e.g. of gravity) will be so radically different so as to not require any form of dark matter to explain the cosmological data.

Now Stanford's point, when applied to this case,${ }^{5}$ would be that this difference of opinion between realists and anti-realists about dark matter will translate into a difference in how much of a reason each side has to encourage astrophysicists to search for currently unconceived alternatives to the concordance model that are 'radically distinct' in the relevant respect, i.e. alternatives according to which there is no dark matter at all in the universe. In so far as realists about dark matter believe that no such alternative could be epistemically superior to the currently accepted concordance model, and in so far as anti-realists about dark matter believe the opposite, Stanford's point would be that dark-matter-realists have

\footnotetext{
${ }^{3}$ I am grateful to Luke Drury for discussion on this topic (although all inaccuracies are my own).

${ }^{4}$ See section 2 for a brief discussion of different forms of scientific realism.

${ }^{5}$ I emphasize again that Stanford himself does not apply his argument to this case, or to any other specific case in contemporary science.
} 
less of a reason to encourage astrophysicists to search for such an alternative. Moreover, we can see clearly how this difference would have real-life practical implications, since labs and funding agencies run by 'dark-matter-realists' would have less strong reasons to do or fund explorative research that explicitly challenges the concordance model as a whole, and the existence of dark matter in particular, as compared to otherwise identical labs and funding agencies run by 'dark-matter-anti-realists'.

Indeed, this difference is not just hypothetical, for although the vast majority of theoretical work in astrophysics is carried out from within the confines of, or with an eye to supplementing, the concordance model, there are also those who seek to challenge it and develop radically distinct alternatives that do not require the existence of dark matter. One such alternative replaces general relativity with a modified version of Newtonian mechanics and gravitation known as Modified Newtonian Dynamics (MOND). It is currently unclear to what extent MOND can account for all the cosmological data explained by the concordance model. Moreover, it is not clear whether MOND could completely avoid having to posit dark matter in any amount. Further research is needed to settle these matters. ${ }^{6}$ This raises the normative issue of whether, or the extent to which, scientists should be carrying out this type of exploratory research rather than looking to improve and extend the current concordance model. If Stanford's argument holds, dark-matter-realists have less reason to encourage this type of exploratory research than would their anti-realist counterparts.

This potential connection between the scientific realism debate and the very practical issue of conservatism in science stands in stark contrast to recently influential 'quietist' ideas that call for dissolving the scientific realism debate in its current form (e.g., Blackburn 2002; Magnus and Callender 2004; see also Fine 1984). If Stanford is right that realism and antirealism diverge in their implications for whether, or the extent to which, theoretical conservatism among scientists should be encouraged or discouraged, then dissolving the debate may well rob us of a philosophical framework for analyzing and adjudicating important science policy proposals such as those of the NSF and the ERC. Moreover, even those of us who have never been particularly convinced by the quietist critics of the scientific realism

\footnotetext{
${ }^{6}$ Further research would also be needed to explore other theoretical alternatives to the concordance model - including some that have never been conceived of - in which dark matter is not required to explain the cosmological data.
} 
debate - and have instead always viewed the question of scientific realism as having intrinsic philosophical worth - also have a reason to take interest in the connection Stanford may have identified between scientific realism and theoretical conservatism. In so far as we agree with NSF and ERC that theoretical conservatism should be discouraged within a given field, Stanford has in effect provided us with a potential argument against scientific realism with regard to the privileged parts of scientific theories in that field. For if Stanford is correct that scientific realism implies that scientists should be encouraged to be theoretically conservative, then realism would simply seem to make the wrong normative recommendation in such cases. Perhaps, then, this would give those of us who were never quite convinced by classic anti-realist arguments a different kind of reason to move towards some form of anti-realism. In short, the argument would be that anti-realism is preferable to realism on the basis of having the more reasonable scientific policy implications of the two views in certain cases.

Of course, all of this depends on whether Stanford is indeed right in claiming that realism and anti-realism have these different implications for whether, or the extent to which, theoretical conservatism should be encouraged or discouraged. In this paper, I argue that the connection between scientific realism and theoretical conservatism is far more complicated than Stanford makes it out to be: Although Stanford is right that realists should be less optimistic than anti-realists about whether scientists are likely to be successful in searching for radically distinct alternatives to the parts of scientific theories that realists take to be at least approximately true, that by itself does not settle the question of whether realists should view theoretical conservatism with regard to those theories (or parts thereof) more favorably than anti-realists. This is in part because realists will place a greater value on having found the relevant kind of radically distinct alternatives, since realists will find it more likely that the new theory, once identified, will turn out to contain a substantial theoretical part that is at least approximately true. Interestingly, realists will also place greater value than anti-realists on unsuccessful searches for radically distinct alternatives, since they provide greater confirmation of current theories for realists than it does for anti-realists. Thus, I will argue that while realists will place a lower probability on a search for radically distinct alternatives being successful, realists will also place a greater value on both possible outcomes of such a search (success and failure). 


\section{Realism and Theoretical Conservatism}

The label 'scientific realism' has been used for a number of different claims about scientific theories; the same is true of 'scientific anti-realism'. In this paper, we will be concerned with the scientific realism debate that roughly concerns whether, or the extent to which, some privileged part of each of our best currently accepted (empirically successful) ${ }^{7}$ scientific theories is probably at least approximately true. ${ }^{8}$ It was once possible to accurately describe this realism debate simply in terms of whether our current best theories were taken to be approximately true (see, e.g., Smart 1963; Boyd 1983; Musgrave 1988), but the positions on both sides are now considerably more nuanced. The overwhelming majority of contemporary realists are selective realists who claim only that certain parts or aspects of our current best theories should be taken as at least approximately true (or correct in some wider sense); and there are a number of different suggestions for which parts or aspects should be selected for this purpose (e.g., Cartwright 1983; Hacking 1983; Worrall 1989; Kitcher 1993; Psillos 1999; Chakravartty 2007; Harker 2013; Peters 2014; see also Saatsi 2016, 2017). Similarly, most antirealists would not disbelieve or suspend judgment on a number of claims made by currently accepted scientific theories, including some claims about unobservable entities. ${ }^{9}$

For this reason, the most accurate way to characterize the relevant debate between realists and anti-realists may well have to proceed on a case-by-case basis, i.e. as being about what attitude one should take towards some specific part of a particular theory. A realist with

\footnotetext{
${ }^{7}$ Since it can safely be assumed that few, if any, of our best currently accepted scientific theories fail to be empirically successful in the relevant sense, I will drop the parenthetical qualification in what follows.

${ }^{8}$ To simplify the discussion, I will often write as if I am treating 'approximately true' as the value of a binary variable (with 'not approximately true' as the other value). In reality, scientific theories and parts thereof can of course be more and less truthlike (i.e. verisimilar, or closer to the truth), and one's probability judgments about how truthlike the relevant claims are could plausibly be taken to be relevant to whether one should count as a scientific realist. Fortunately, nothing in what follows requires that 'approximately true' be taken as a binary variable. On the contrary, my analysis of Stanford's argument below in terms of 'expected scientific value' can accommodate degrees of approximate truth, since the term in which approximate truth enters the argument, i.e. 'scientific value', is taken to be gradable in this analysis.

${ }^{9}$ For example, Stanford himself notes that he takes a skeptical position only with regard to claims about "fundamental theories of nature" (2006: 32), and explicitly notes that his arguments do not carry over to all claims about unobservable entities (such as those based on microscopic evidence; see Stanford 2006: 33).
} 
regard to such a theory-part will claim that the theory-part in question is more probably approximately true than a corresponding anti-realist about that theory-part. More precisely, the available positions in this debate would fall on a spectrum from greater to lesser probability that the relevant theory-part is at least approximately true, with 'realism' vaguely referring to positions that fall somewhere on the greater-probability side of the spectrum and 'anti-realism' vaguely referring to those on the opposite side. In this particular scientific realism debate, a number of issues often associated with the label 'scientific realism' are not up for debate - e.g., whether scientific theories have truth values like other factual claims; whether sentences containing theoretical terms should be interpreted literally; or whether unobservable entities exist independently of our minds or theories. ${ }^{10}$

The debate about whether a given theory or theory-part is probably approximately true is also distinct from the debate about whether science aims to give us theories that are true (or approximately true). In the latter debate, an anti-realist is someone who argues that the aim of science is something less than truth, such as empirical adequacy (van Fraassen 1980). To distinguish the two debates, the former variety of realism is sometimes referred to as 'epistemic scientific realism', while the latter is referred to as 'axiological scientific realism' (e.g., Lyons and Clarke 2002: x). Later in this paper (section 6), I discuss whether combining epistemic anti-realism with axiological anti-realism of this kind makes a difference to Stanford's contention that anti-realists have more reason to discourage theoretical conservatism than realists. For most of the paper, however, I will assume that both parties to the relevant scientific realism debate accept that science aims at true (or approximately true) theories; the disagreement between the relevant kind of realists and anti-realists is thus merely about the extent to which this aim has probably been reached in our corpus of currently accepted theories.

Another (indirect) way to identify the realism debate that we shall be concerned with in this paper is by the most prominent arguments in favor of the positions on each side. On the realist side, the No-Miracles Argument (NMA) has traditionally been taken to be the strongest - or even 'ultimate' (Musgrave 1988) - argument for an epistemic form of scientific

\footnotetext{
10 Stanford $(2000,2006)$ is quite explicit about answering these questions in ways traditionally associated with 'scientific realism'. The same is true of most historically-motivated anti-realists these days, with the notable exception of Rowbottom (2011); see also Frost-Arnold (2014).
} 
realism. In short, the argument is that the best explanation for the amazing empirical success of contemporary science is that some relevant parts of the theories that enjoy this success are for the most part at least approximately true; otherwise, the empirical success of science would be a 'miracle' (Smart 1963; Putnam 1975; Boyd 1983; Psillos 1999; Sprenger 2016; Henderson 2017; Dawid and Hartmann forthcoming). On the anti-realist side, the Pessimistic Meta-Induction (PMI) starts by noting that most empirically successful theories that were accepted in the past have turned out to be radically false (i.e., not approximately true). By a simple enumerative induction over the history of science, it is then inferred that current best theories (or some relevant parts thereof) will probably also be shown to be false by later scientific developments (Poincaré 1952/1905; Hesse 1976; Putnam 1978; Laudan 1981; Wray 2015).

Stanford's own (2006) version on this argument - what he calls the 'new induction over the history of science' - avoids some of the problems that plagued the original PMI (e.g., Lipton 2000; Lewis 2001; Lange 2002; Roush 2009; Fahrbach 2011, 2017). The key difference between the PMI and Stanford's 'new induction' is that whereas PMI is an induction from past to current theories, Stanford's induction infers from past to current theorists (Magnus 2010). In particular, Stanford appeals to the historical record of scientists failing to conceive of radically distinct alternatives to then-accepted theories that were (or would have been) at least as well confirmed by then-available evidence. Stanford claims that this problem of unconceived alternatives is ubiquitous in the history of science, and infers that current scientists are probably in the same boat. The intended upshot is that currently accepted scientific theories are unlikely to be approximately true; rather, these theories are probably merely the best theories that scientists have currently managed to conceive of - with better alternatives still waiting to be discovered in unexplored logical space. In the end, then, Stanford draws a similar conclusion as the original PMI - i.e. a form of scientific anti-realism - but he does so through an indirect route involving an induction over scientists' imaginative capacities.

Stanford's influential case for anti-realism has been widely discussed, and criticized, elsewhere (e.g., Chakravartty 2008; Forber 2008; Godfrey-Smith 2008; Devitt 2011; Ruhmkorff 2011, 2015; Saatsi 2015; Egg 2016; Frost-Arnold 2016; Dellsén 2017). Here I am concerned with Stanford's more recent claim that realism and anti-realism have different 
implications for whether scientists should be encouraged or discouraged to be theoretically conservative. Stanford does not explicitly define 'theoretical conservatism' or its cognates, ${ }^{11}$ but it's clear that he is referring to the tendency to work within an existing theoretical framework rather than seeking to identify and develop radically distinct alternatives that could subsequently be shown to be epistemically superior to (i.e., more empirically successful than) currently accepted theories. ${ }^{12}$ So understood, theoretical conservatism is clearly a matter of degree - and since there is clearly some value both in searching for radically distinct alternatives of this sort, and in spending one's time and resources on other scientific activities, the appropriate amount of theoretical conservatism will presumably involve striking some sort of balance between these two considerations. Thus the question is plausibly not whether, but the extent to which, scientists should be theoretically conservative.

Stanford's contention is that this question should be answered differently by scientific realists and their anti-realist opponents. Stanford's key thought is that the extent to which scientists will be successful in their attempts to identify and develop radically distinct, epistemically superior alternatives to current theories will depend on how likely it is that there are no such epistemically superior alternatives to currently accepted theories to be found in the first place. After all, a search for something that is non-existent is clearly less likely to be successful than an otherwise similar search for something that does exist. Since realists and anti-realists will differ in their opinions as to whether superior alternatives to current theories are likely to exist, they will also differ in their opinions regarding the likelihood of success when searching for such alternatives. Whereas the anti-realists will view the search for new theoretical paradigms as "one of the most important ambitions of the scientific enterprise", the scientific realist

[...] should be perfectly happy to rule out consideration of lines of research or theoretical proposals that are radically or fundamentally at odds with existing theories, as she thinks it quite unlikely that any of these will ultimately come to be accepted in the future (Stanford 2015b: 874).

\footnotetext{
${ }^{11}$ Stanford uses 'conservatism' and 'conservativeness' interchangeably as labels for a tendency or practice (as opposed to a thesis or doctrine). I will follow Stanford's lead in this respect.

${ }^{12}$ I will refer to these theories as 'radically distinct, epistemically superior alternatives', or sometimes (for brevity) just 'radically distinct alternatives'.
} 
Now, Stanford presents his argument as being concerned with 'existing' theories quite generally, but (as we have seen) most contemporary realists and anti-realists are more discerning in their attitudes towards different parts of our current best theories. However, it would be premature to conclude that Stanford's argument therefore gains no foothold in the current realism debate, for his argument can be recast in terms of any given specific theorypart about which realists and anti-realists might disagree. To see this, let $\mathrm{P}_{\mathrm{T}}$ be the theorypart in question; for example, in the case of realists and anti-realists about dark matter, $\mathrm{P}_{\mathrm{T}}$ would be the claim that there exists invisible ('dark') matter that makes up around $27 \%$ of the universe's total mass-energy. Then Stanford's point translates to the claim that realists and anti-realists about dark matter will differ in their estimations of how likely it is that a radically different theory-part $\mathrm{P}_{\mathrm{T}}{ }^{*}$ (e.g. the claim that all the matter in the universe is of the more familiar, non-dark, kind) will become accepted in the future. As a result, the argument would continue, dark-matter realists "should be perfectly happy to rule out consideration of lines of research or theoretical proposals" that involve attempts to identify and develop theories with theory-parts such as $\mathrm{P}_{\mathrm{T}}{ }^{*}$. In sum, then, Stanford's argument - suitably reconstructed - applies with equal force to the more piecemeal, case-by-case realism debate in contemporary philosophy of science.

The question, then, is whether Stanford's argument is sound in either its original formulation or when reconstructed to apply in a more piecemeal way to specific theories or theory-parts. I will argue that it is not. In brief, this is because Stanford's analysis overlooks the impact one's stance in the debate over scientific realism will have on the value of different outcomes of the relevant type of search: While Stanford is right that realists have reason to be less optimistic that a radically distinct, epistemically superior alternative to a given theory (or parts thereof) will be found, realists will also place a greater value on each of the two possible outcomes of such a search (i.e., success and failure). In order to develop this objection, I will now take a step back and discuss how to approach the issue of whether scientists should be theoretically conservative from the perspective of a standard framework in normative decision theory, viz. expected utility theory. This should not be a surprising or controversial methodological choice, since the question of whether scientists should search for radically distinct alternatives is clearly a decision-theoretic problem rather than, say, a 
purely epistemic one - it concerns not (merely) what scientists should believe, but what they should do. ${ }^{13}$

\section{A Decision-Theoretic Analysis}

Expected utility theory holds that in situations of uncertainty, one should prefer the available course of action that has the highest expected utility, where 'expected utility' is the probability-weighted average of the utilities of the possible outcomes of the action. Formally, the expected utility of an act $A, E U(A)$, is calculated by multiplying the utility of each possible outcome $o_{i}$ of $A$ with the conditional probability of $o_{i}$ given $A$, and then taking the sum of these products:

$$
E U(A)=\sum_{i} U\left(o_{i}\right) \operatorname{Pr}\left(o_{i} \mid A\right)
$$

Before applying this framework to the issue of theoretical conservatism, we need only make one slight modification. Our concern is with whether encouraging scientists to be theoretically conservative is good science policy according to realists and anti-realists respectively. But there are many kinds of 'utility' that will be irrelevant to that kind of problem, e.g. the utilities derived from personal preferences of individual scientists. So our concern is not simply with what would maximize expected utility tout court, but with what would maximize a specifically scientific kind of utility - what I shall refer to as 'scientific value'. I will accordingly replace ' $\mathrm{U}$ ' with 'SV' (for scientific value) and 'EU' with 'ESV' (for expected scientific value). I will shortly (section 4) make an assumption about what the realist and antirealist take scientific value to consist in, but later on (section 6) I will also consider whether relaxing this assumption makes a difference to my analysis.

Now, the course of action that is relevant to the issue of theoretical conservatism is to spend some given time or resource on explicitly or implicitly searching for or developing radically distinct, epistemically superior alternatives to currently accepted theories (or parts thereof). An example would be astrophysicists who are, explicitly or implicitly, spending time

\footnotetext{
${ }^{13}$ Note also that since the issue here is normative, I will be employing normative rather than descriptive decision theory in the following analysis. In contrast to its descriptive cousin, normative decision theory does not assume that agents are perfectly rational. Indeed, the following analysis makes no assumptions whatsoever about whether (or the extent to which) scientific agents are rational.
} 
and resources on developing alternatives to the concordance model that do not require dark matter, such as those based on MOND. For brevity, I will refer to this type of activity as 'SEARCH'.${ }^{14}$ On the simplest way of partitioning logical space, there are exactly two possible outcomes of such a search: (i) finding a theory, and (ii) not finding a theory. I will refer to these outcomes as 'SUCCESS' and 'FAILURE' respectively. The expected scientific value of the anti-conservative course of action, i.e. SEARCH, is then simply given by:

$$
\text { ESV }(\text { SEARCH })=\text { SV(SUCCESS) } \operatorname{Pr}(\text { SUCCESS } \mid \text { SEARCH })+\text { SV(FAILURE) } \operatorname{Pr}(\text { FAILURE } \mid \text { SEARCH })
$$

Since SUCCESS and FAILURE are collectively exhaustive outcomes given SEARCH, their probabilities conditional on SEARCH sum to one. We can thus simplify as follows:

$$
\text { ESV }(\text { SEARCH })=\text { SV(SUCCESS) Pr(SUCCESS|SEARCH) + SV(FAILURE) }(1-\operatorname{Pr}(\text { SUCCESS } \mid \text { SEARCH }))
$$

This brings out that the expected scientific value of searching for radically distinct alternatives depends on exactly three (independent) factors: (i) the scientific value of finding such an alternative, SV(SUCCESS); (ii) the scientific value of failing to do so, SV(FAILURE); and (iii) the probability of finding a radically distinct alternative given that one searches for it, $\operatorname{Pr}\left(\right.$ SUCCESS $\mid$ SEARCH) ${ }^{15}$

We are now in a position to see what is missing from Stanford's analysis of the implications of realism and anti-realism on the extent to which theoretical conservatism

\footnotetext{
${ }^{14}$ I have deliberately not specified how much resources are put into a given search, because my discussion below does not depend on this specification. The question I am seeking to answer is, for any given amount of resources, whether the expected scientific value of devoting them to searching for alternatives is greater or lesser given realism or anti-realism about the theory-part in question. That said, if you prefer, you can think of the resources as being of some specific amount, e.g. one work week of one average scientist (or a material resource of equivalent monetary value).

${ }^{15}$ As always, assigning probabilities and utilities to different outcomes is a nontrivial matter, (and in some cases these quantities may be vague - in which case they would be represented by numerical intervals rather than single numbers). Nevertheless, formalizing the decision situation in this way illuminates the ways in which it depends on the relative scientific values and probabilities assigned by realists and anti-realists respectively, and explains why certain seemingly-correct inferences are in fact faulty (as I argue extensively below). Furthermore, it should be noted that many of the difficulties of assigning scientific values and probabilities are avoided in the current context since the discussion below depends only on comparative (as opposed to absolute) assignments to these terms, e.g. that $S V_{r}\left(\right.$ FAILURE) $>S V_{a}$ (FAILURE). In such comparative assignments, we can ignore factors that contribute equally to both items that are being compared. Thus, for example, we can presumably ignore the possibility that a given search, even if it is a failure with respect to finding a better alternative, leads to interesting results about some other theoretical issue or question, since the contribution of such an event to scientific value can be expected to be at least roughly equal for the realist and the antirealist.
} 
should be encouraged or discouraged. Formulated within the framework of expected utility theory, Stanford's argument is essentially that the realist's expected scientific value of searching for radically distinct alternatives, $\operatorname{ESV}_{r}(\operatorname{SEARCH})$, is lower than that of the antirealist, $\mathrm{ESV}_{\mathrm{a}}(\mathrm{SEARCH})$, because the realist will assign a lower probability to finding such an alternative than the anti-realist, i.e. because $\operatorname{Pr}_{r}($ SUCCESS $\mid$ SEARCH $)<\operatorname{Pr}_{a}($ SUCCESS $\mid$ SEARCH $)$. This argument implicitly assumes, fairly reasonably, that both the realist and the anti-realist will place a higher scientific value on finding a radically distinct theory than on failing to do so, i.e. that $\mathrm{SV}_{\mathrm{r}}($ SUCCESS $)>S V_{r}\left(\right.$ FAILURE) and $\mathrm{SV}_{\mathrm{a}}(\mathrm{SUCCESS})>S \mathrm{~V}_{\mathrm{a}}($ FAILURE). I will not contest that assumption here.

But even with that assumption in place, Stanford's argument is still not valid on this reconstruction. The problem is that the realist and anti-realist may place different scientific values on finding and not finding radically distinct theories (even while satisfying the implicit assumption that each of them places greater scientific value on finding a new theory than on failing to do so). So the argument will also need to assume that the scientific values of finding and not finding a radically distinct alternative are the same (or lower) for the realist and the anti-realist, i.e. that $\mathrm{SV}_{r}(\mathrm{SUCCESS}) \leq \mathrm{SV}_{\mathrm{a}}$ (SUCCESS) and $\mathrm{SV}_{\mathrm{r}}($ FAILURE $) \leq \mathrm{SV}_{\mathrm{a}}$ (FAILURE). ${ }^{16}$ If these assumptions are added, the argument is clearly valid. But the problem now is that Stanford provides absolutely no reason to think that these conditions are satisfied. Moreover, I shall shortly argue that we have good reasons to think that both conditions fail, i.e. that $\mathrm{SV}_{\mathrm{r}}($ SUCCESS $)>\mathrm{SV}_{\mathrm{a}}($ SUCCESS $)$ and $\mathrm{SV}_{\mathrm{r}}($ FAILURE $)>S V_{\mathrm{a}}($ FAILURE). Specifically, section 4 argues that the first condition fails; section 5 argues that the second fails as well.

Let me note at the outset that this is not to say that the realist's expected scientific value of searching for radically distinct alternatives, $\mathrm{ESV}_{\mathrm{r}}(\mathrm{SEARCH})$, will necessarily be as high as (or higher than) that of the anti-realist, $\mathrm{ESV}_{a}(\mathrm{SEARCH})$. Thus, while I will argue below that Stanford's argument is not convincing, I would not claim that my arguments also establish that Stanford's conclusion is false. After all, it might be that, at least in some cases, the extent to which the anti-realist assigns a higher probability than the realist to finding a radically distinct alternative outweighs the extent to which the realist places greater scientific value

\footnotetext{
${ }^{16}$ Note that this assumption can be false even if the implicit assumption mentioned in the previous paragraph is true, since the former compares scientific values for the same outcomes across the realist/anti-realist divide and the latter compares the scientific values for different outcomes placed by the realist and anti-realist respectively.
} 
than the anti-realist on finding - and, indeed, on not finding - such an alternative. ${ }^{17}$ So Stanford may end up being right that realists should, at least in some cases, be friendlier towards theoretical conservatism than anti-realists. But, of course, this consideration cuts both ways - just as a probability difference between realists and anti-realists could presumably outweigh a difference in the scientific values each places on the two possible outcomes, so too the latter could presumably outweigh the former. In that case, the upshot may well be that realists should be more inclined towards conservatism in some circumstances, while anti-realists should be more inclined towards it in others.

Before we delve into the argument, it is also worth emphasizing that we are here contrasting the expected scientific value assigned to a single course of action, viz. what I have called SEARCH, assigned by realists and anti-realists respectively. This is meant to measure how much of a reason realists and anti-realists respectively have to spend time and resources searching for radically distinct alternatives to current theories (or theory-parts). Of course, realists and anti-realists could also differ in how much of a reason they have to engage in other scientific activities, such as working on more 'conservative' projects that build on or develop current theories (or theory parts). In particular, one could argue that since the realist believes that a given theory (or theory part) is at least approximately true, she should assign a higher expected scientific value than the anti-realist to working on research projects of this kind. However, it's important to see that such a situation is perfectly compatible with the realist also assigning a higher expected scientific value to the 'anti-conservative' search for radically distinct alternatives to current theories. In that case, the realist would value both kinds of scientific projects more than her anti-realist counterpart - thus in effect valuing science as a whole more than the anti-realist. By contrast, Stanford's argument is that the realist has less of a reason than the anti-realist to value searching for alternatives to current theories (or theory parts), regardless of whether the realist has more reason to value other kinds of projects.

\footnotetext{
${ }^{17}$ This might seem counterintuitive or even paradoxical. After all, ESV ${ }_{r}(S E A R C H)$ and ESV $_{a}(S E A R C H)$ are

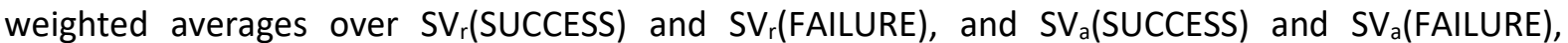
respectively. So how could the weighted average over the greater pair of values possibly be lower than that of the lesser pair? The answer is that the weights - i.e. the probabilities of SUCCESS and FAILURE, conditional on SEARCH - are not held constant through the comparison. This phenomenon has some structural similarities to Simpson's paradox (see, e.g., Malinas and Bigelow 2016), and may be somewhat counterintuitive for similar reasons.
} 


\section{The Scientific Value of Radical Change}

I will start by considering what scientific values the realist and the anti-realist should place on finding a radically distinct, epistemically superior alternative to a currently accepted theory. As noted, Stanford's argument (when reconstructed in a decision theoretic framework) relied on the assumption that the anti-realist should place at least as much scientific value on such an outcome as the realist, i.e. that $\mathrm{SV}_{r}(\mathrm{SUCCESS}) \leq \mathrm{SV}_{\mathrm{a}}$ (SUCCESS). Here I will argue that the opposite is true, i.e. that $\mathrm{SV}_{\mathrm{r}}\left(\right.$ SUCCESS) $>\mathrm{SV}_{\mathrm{a}}$ (SUCCESS). In order to get to this argument, however, we must first consider - if only briefly - the more fundamental question of what determines the scientific value of a given outcome. In virtue of what is one outcome more scientifically valuable than another?

The most straightforward answer to this question is that outcomes are scientifically valuable to the extent that they ultimately (as opposed to immediately) promote the discovery of (empirical and theoretical) truths in the relevant domain. ${ }^{18}$ For the purposes of the arguments in this section and the next one, I will assume that something like this answer is common ground between the realist and the anti-realist of the sort we are concerned with here. ${ }^{19}$ However, I do concede that some self-described anti-realists might well dispute that scientific value can be characterized in terms of what promotes truth in this sense. In particular, since constructive empiricists (van Fraassen 1980, 2001) hold that the aim of science is empirical adequacy rather than truth, they would presumably insist that scientific value should be defined in terms of promoting empirical adequacy as opposed to truth. Recall, however, that I have explicitly set such an 'axiological' form of anti-realism aside for most of this paper, instead focusing on the 'epistemic' kind of anti-realism that merely denies that currently accepted theories are probably approximately true. This form of anti-realism does not dispute that the aim of science is to discover truths about the world, but advocates for a

\footnotetext{
${ }^{18}$ Of course, anti-realists will typically be more skeptical that we have in fact discovered, or even that we could discover, theoretical truths than their realist counterparts. But anti-realists of the epistemic variety discussed in section 2 need not dispute that discovering theoretical truths would be scientifically valuable (if and in so far as it is possible to do so).

${ }^{19}$ I say that 'something like' this answer will be assumed to be correct, because I want to allow here that scientific value consists in promoting something that entails truth or approximate truth, e.g. knowledge (Bird 2007, 2015) or understanding (Potochnik 2015; Dellsén 2016). I also want to allow that some truths are more scientifically valuable than others due to their 'significance' (Kitcher 2001).
} 
pessimistic or skeptical view of the extent to which this aim has been reached. Of course, there remains a legitimate question of whether the arguments of this section and the next would go through if historically motivated anti-realists like Stanford also adopted the constructive empiricist view of the aim of science. I will consider that issue in a separate section below (section 6).

Assuming then, for now, that the realist and anti-realist agree that an outcome has scientific value to the extent that it promotes the discovery of truths, we can start to think about the scientific value, from the realist and anti-realist perspective, of finding a radically distinct, epistemically superior alternative to a currently accepted theory (or theory-part). Recall at this point that what I have been referring to as 'radically distinct, epistemically superior alternatives' are theories that are not just radically distinct from currently accepted theories (with respect to some specific theory-part to which the realist is committed), but also such that were they to be identified, developed, and tested, they would replace currently accepted theories (hence 'epistemically superior'). By the realist's lights, the newly proposed alternatives (or relevant parts thereof) will be significantly more likely to be true than the previously accepted theories (or relevant parts thereof) - after all, these theories will be tested against each other by scientific observation and experimentation (as, e.g., relativity theory was tested against classical mechanics), with the loser being almost certainly false by the realist's lights and the winner quite probably, although not certainly, at least approximately correct regarding the relevant theory-part. So, according to the realist, having identified and developed a radically distinct alternative that is in fact epistemically superior to currently accepted theories has clear scientific value in that it makes it much more probable that what we end up with is a theory or theory-part that is at least approximately true.

Compare this to how things look from the point of view of an anti-realist who believes that a given accepted theory is probably radically false (i.e., not approximately true). While she values truth just as much as the realist, this anti-realist will be less optimistic that the truth (or an approximation thereto) has been obtained at any given moment - including possible moments in the future in which a radically distinct alternative has replaced a theory that was previously accepted. After all, the anti-realist will at that point remind herself that most theories that were accepted in the past - including those that became accepted after replacing other theories that had been accepted even earlier - are radically false. And so she 
will (once again) infer inductively that the theories that have now become accepted, including the relevant radically distinct alternative, is probably also radically false. Indeed, this historical (PMI-style) argument has only become stronger at a point in the future in which yet another theory is replaced by a radically distinct alternative, so if anything the anti-realist should be even more pessimistic at that point than she was before about the prospects of a given accepted theory being approximately true.

This is relevant for the scientific value that the anti-realist should place on identifying and developing radically distinct alternatives because, unlike the realist, the anti-realist cannot say that the radically distinct alternative (or some relevant part of that alternative theory) is much likelier to be true than the previous theory (or theory-part). At the very least, the difference in probability between a superseded and a superseding theory (or theory-part) being approximately true will be considerably greater for the realist than for the anti-realist. But then, if scientific value consists in promoting the discovery of truths, the value of replacing a theory in this manner - by identifying a radically distinct alternative, and subsequently showing it to be superior to an accepted theory - will also be greater for the realist than for the anti-realist. After all, while both parties can agree that the process is likely to have led to a more empirically successful theory, the realist will find it much more likely than the antirealist that the process has also led to the discovery of an (approximate) truth regarding phenomena that weren't directly involved in establishing the new theory's empirical success. In short, then, we have reason to believe that $\mathrm{SV}_{r}($ SUCCESS $)>\mathrm{SV}_{\mathrm{a}}($ SUCCESS $)$.

The upshot of this for Stanford's argument is that we cannot conclude that ESV $_{r}(\mathrm{SEARCH})<\mathrm{ESV}_{\mathrm{a}}(\mathrm{SEARCH})$ from the fact that $\operatorname{Pr}_{\mathrm{r}}(\mathrm{SUCCESS} \mid \mathrm{SEARCH})<$ $\operatorname{Pr}_{\mathrm{a}}(\mathrm{SUCCESS} \mid \mathrm{SEARCH})$ - even assuming that $\mathrm{SV}_{\mathrm{r}}($ SUCCESS $)>\mathrm{SV}_{\mathrm{r}}\left(\right.$ FAILURE) and $\mathrm{SV}_{\mathrm{a}}(\mathrm{SUCCESS})$ $>\mathrm{SV}_{\mathrm{a}}($ FAILURE). That is, we cannot conclude that the expected value of searching for radically distinct, epistemically superior alternatives is lower for the realist than the anti-realist from the fact that the probability of finding such a theory is higher by the anti-realist's lights - even assuming that both parties place a higher scientific value on finding such a theory than on failing to do so. This is because the realist will place a higher scientific value on finding such a theory than the anti-realist, due to the fact that any such alternative will by the realist's lights be more likely to be (or contain a theory-part that is) approximately true. 
Note that none of this is to deny that the anti-realist might very well, in good instrumentalist fashion, see plenty to scientific value in replacing a scientific theory with a more empirically successful alternative - regardless of whether the later theory is 'closer to the truth' (generally or with regard to the theory-part in question). Such an anti-realist will see scientific value in such a change because the later theory will be a better instrument for predicting and manipulating the observable world around us. However, the realist will of course also find exactly the same feature to be of scientific value as well, even if she will insist that this is not the only thing of value in the change. The realist does not deny that later theories will be better qua instruments for predicting and manipulating observables (or that having better theoretical instruments in this sense is scientifically valuable); rather, the realist contests the instrumentalist's claim that the theory does not also probably correctly represent some relevant parts or aspect of the unobservable realm. Since the relevant type of instrumental progress will be scientifically valuable to both the realist and the anti-realist, it cancels out in a comparison between the scientific values assigned by each party, i.e. in estimating the comparative values of $\mathrm{SV}_{\mathrm{r}}(\mathrm{SUCCESS})$ and $\mathrm{SV}_{\mathrm{a}}$ (SUCCESS).

\section{The Scientific Value of Failed Searches}

Having argued that the realist should place greater scientific value on successful searches for radically distinct, epistemically superior alternatives than the anti-realist - i.e., that $\mathrm{SV}_{\mathrm{r}}(\mathrm{SUCCESS})>\mathrm{SV}_{\mathrm{a}}(\mathrm{SUCCESS})-\mathrm{I}$ will now argue for the more surprising claim that the realist should also place greater scientific value on failed searches of this kind - i.e., that $\mathrm{SV}_{\mathrm{r}}($ FAILURE $)>\mathrm{SV}_{\mathrm{a}}($ FAILURE $)$. These claims are not in conflict - after all, one person can place greater value on both or all possible outcomes of an act than another person. ${ }^{20}$ Nevertheless, it is certainly not obvious why the realist should place any scientific value at all on failing to find a radically distinct, epistemically superior alternative, since that would not lead to any change in the theories accepted by the scientific community at a given time. So let me start by arguing that the realist should place some scientific value on failing to find a radically distinct alternative, and then suggest that the anti-realist should place less value on it.

\footnotetext{
${ }^{20}$ For example, I might enjoy winning in Scrabble more than you, while also enjoying losing more.
} 
My argument that the realist should place some scientific value on failing to find a radically distinct, epistemically superior alternative rests on the idea that failing to find such an alternative constitutes an unusual kind of evidence for the accepted theory. This idea may be most familiar from methodological debates in fundamental physics, where it has been argued - correctly, I think - that the fact that there is currently no plausible theoretical alternative to string theory, despite great efforts to identify and develop such a theory, is at least some evidence for string theory itself (Dawid 2009, 2013). How exactly failures to find alternatives to a given theory could constitute evidence for it has recently been spelled out in some detail within a Bayesian framework under the label of the 'no alternatives argument' (Dawid, Hartmann and Sprenger 2015; see also Hertzberg 2014), but the intuitive idea can be simplified and stated in rough outlines as follows: ${ }^{21}$

If an accepted theory $\mathrm{T}$ is not even approximately true, then there must be at least one radically distinct alternative theory that is approximately true. If identified and developed, this alternative theory will eventually be shown to be superior to our currently accepted theory $\mathrm{T}$ by scientific testing. By contrast, if $\mathrm{T}$ is approximately true, then no such radically distinct alternative theory will be shown to be epistemically superior to T - after all, since $T$ would be approximately true, any theory that is epistemically superior to $T$ would be similar to, i.e. not radically distinct from, T. Hence the likelihood of finding a radically distinct alternative that is superior to $T$ is greater if $T$ is not approximately true than if it is. In a Bayesian framework, such a difference in likelihoods entails that failing to find a radically distinct and superior alternative to $\mathrm{T}$ incrementally confirms, i.e. is some evidence for, $\mathrm{T}$ itself. Very briefly put, the point here is that failing to find a radically distinct, epistemically superior alternative to a theory $\mathrm{T}$ is some evidence for $\mathrm{T}$ being approximately true, since our failing to find such a theory is exactly what we should expect if $\mathrm{T}$ is indeed approximately true.

Of course, to say that this is some evidence for T being approximately true is not to say that it could, by itself, make T's approximate truth be sufficiently well supported to be accepted or believed outright. As noted, the kind of evidential support at issue here is incremental, as opposed to absolute, confirmation (Carnap 1962). Thus it is consistent with what I have said so far that failed searches provide only a tiny amount of confirmation for T's

\footnotetext{
${ }^{21}$ For simplicity, I present the following argument schema as being concerned with evidence for an entire theory, but the argument schema holds mutatis mutandis for a given part of such a theory.
} 
approximate truth. Whether it is indeed tiny will very much depend on the specifics of the case, but there are cases in which the amount of confirmation obtained in this way is arguably far from tiny. For example, Dawid (2017) argues that many physicists were quite confident of the existence of the Higgs boson even before strong empirical confirmation was obtained, on the grounds that no theoretical alternatives had been found that would explain, e.g., the observed mass spectrum of elementary particles. Thus it would certainly be a mistake to ignore this type of confirmation in an estimation of the expected scientific value of searching for theoretical alternatives.

Assuming, then, that failing to find the relevant kind of alternative to $T$ is some (incremental) evidence for T's approximate truth, a scientific realist will find this scientifically valuable for the same reasons as she finds other kinds of evidence to be of scientific value. In general, the realist can point out that scientists with more evidence will be more likely to accept hypotheses that are true or approximately true (Maher 1990; see also Horwich 1982). Thus having more evidence - including having more of the somewhat unusual kind of nonempirical evidence discussed above - is indeed scientifically valuable in virtue of indirectly promoting the scientific goal of accepting true theories within a given domain. This is at least how things will look from the realist's point of view, who will have no reason to be sceptical of the idea that failure to find an alternative to a theory is a reason to believe that the theory is at least approximately true.

By contrast, consider the issue from the point of view of historically-motivated antirealists such as Stanford himself. Could they argue that failing to find radically distinct, epistemically superior alternatives is evidence for currently accepted theories in the same way? They might, but hardly to the same extent that the realist would be prepared to. After all, in so far as failing to find such alternatives to current theories constitutes evidence for those theories, we should be more confident that currently accepted theories (or relevant parts thereof) are indeed approximately true. Since anti-realists of the relevant kind are precisely concerned with denying that currently accepted theories (or their relevant theoryparts) are probably approximately true, they cannot very well endorse a type of evidence that speaks directly for those theories' approximate truth - or, at the very least, they would surely take such evidence as less confirmatory than their realist counterparts (on pain of having to 
adopt a more realist attitude towards the theoretical claim in question, e.g. the existence of the Higgs boson (Dawid 2017)).

Indeed, it is worth noting that at least some anti-realists have principled reasons for viewing failed attempts at finding radically distinct theories (or theories with radically distinct theory-parts of the relevant kind) as less strongly confirmatory than their realist opponents. Stanford (2006; 2015a) himself provides the strongest reasons of this sort, when he argues as part of his 'new induction' - that both past and contemporary scientists generally have a considerably more limited scientific imagination than realists have tended to assume. To the extent that Stanford is right (and the realist is wrong) about this empirical point, each failed attempt to find a radically distinct alternative to an accepted theory (or theory-part) would be weaker evidence for the accepted theory's (or theory-part's) truth. So, in effect, the considerations Stanford appeals to in his 'new induction' would, if true, undermine the type of non-empirical evidence that I discussed above. The anti-realist of this 'stanfordite' variety thus has a principled argument for viewing this type of evidence as less strongly confirmatory than the realist does.

The upshot of all of this is that, all other things being equal, an anti-realist - especially one of the 'stanfordite' variety - would view failed attempts at finding radically distinct, epistemically superior alternatives as less strong evidence for accepted theories than her realist counterpart. At least in this respect, then, our anti-realist will view such failed attempts as less scientifically valuable than the realist. But of course this means that the anti-realist must also accept that, all other things being equal, the realist places greater scientific value than she does on failed attempts to find radically distinct alternatives to currently accepted theories. ${ }^{22}$ In sum, then, we have here another reason why we cannot conclude that the expected value of searching for radically distinct, epistemically superior alternatives is lower for the realist than the anti-realist from the fact that the probability of finding such a theory is higher by the anti-realist's lights - even assuming that both parties place a higher scientific value on success than on failure. This time around, this is because the realist arguably has

\footnotetext{
${ }^{22}$ Of course, this does not preclude there being other reasons for the anti-realist to assign a higher value to failed searches than the realist which aren't matched by equally strong reasons for the realist to do so. In that case, other things would not be equal. While I have not been able to think of any such reasons, I have no argument that such reasons cannot in principle be provided - hence the ceteris paribus clause in the main text.
} 
reason to place a higher scientific value than the anti-realist on failing to find a radically distinct, epistemically superior alternative to a currently accepted theory, which is in turn due to the fact that the realist will view such a failure as being more confirmatory of accepted theories (or theory-parts) than the anti-realist.

\section{Combining Epistemic Anti-Realism with Constructive Empiricism}

So far I have been assuming that realists and anti-realists disagree only about the extent to which current best theories (or parts thereof) are probably approximately true (and directly related issues, such as the extent to which the history of science undermines the epistemic status of current best theories, parts thereof). In particular, I have assumed that the relevant type of realists and anti-realists agree that science aims at giving us true theories - an axiological thesis that van Fraassen (1980) somewhat idiosyncratically takes to be partly definitive of scientific realism. But what if our anti-realist follows van Fraassen in taking the aim of science to be something less than truth? In particular, what if our anti-realist is not merely an epistemic anti-realist, but also a constructive empiricist who takes the aim of science to be empirical adequacy - roughly, correctness with regard to the observable aspects of the world?

Given the constructive empiricist's view of the aim of science, such an anti-realist will presumably reject our previous assumption that outcomes are scientifically valuable to the extent that they promote the discovery of truths. Rather, the scientific value of an outcome would be defined in terms of the extent to which it promotes empirical adequacy. For our purposes, the question is whether this should significantly alter the anti-realist's estimation of the expected scientific value of searching for radically distinct, epistemically superior alternatives to our best current theories (or relevant theory-parts). There is a good case to be made that it does. After all, such a constructive empiricist could claim that radical changes in theory were necessary for gaining gradual increases in empirical adequacy. As such, constructive empiricists could argue both that the probability of finding radically new theories is high relative to realists, and also that the scientific value of such findings will be high relative to truth-seeking anti-realists. The constructive empiricist may thus seem to be in the strongest 
position of all to argue that the expected scientific value of searching for radically new theories is high. ${ }^{23}$

Although I concede that moving from truth-seeking anti-realism to this type of constructive empiricism changes both the probability of finding radically distinct alternatives, and the scientific value of doing so, I still don't think we will find here a sound Stanford-style argument for the conclusion that realists should be friendlier towards theoretical conservatism than their anti-realists counterparts (in this case, constructive empiricists of a particular stripe). ${ }^{24}$ To see why, note first that while the envisaged constructive empiricist would plausibly assign a higher probability than our realist to finding an epistemically superior alternative to current theories, our original anti-realist will assign an even higher probability to the same event. After all, in contrast to the constructive empiricist, our original anti-realist does not claim that current best theories are even empirically adequate (or approximately so); indeed, the historical PMI-style arguments to which she appeals cut equally against the constructive empiricist claim that current theories are (approximately) empirically adequate as the realist claim that they are (approximately) true. ${ }^{25}$ Using the subscript ' $c$ ' to denote the constructive empiricist probability assignments, we can sum this up in our earlier terminology as follows:

$$
\operatorname{Pr}_{r}(\text { SUCCESS } \mid \text { SEARCH })<\operatorname{Pr}_{c}(\text { SUCCESS } \mid \text { SEARCH })<\operatorname{Pr}_{\mathrm{a}}(\text { SUCCESS } \mid \text { SEARCH })
$$

So, with regard to the probabilities of finding a radically distinct, epistemically superior alternative, the constructive empiricist in effect occupies a middle ground between the realist and our original anti-realist.

The next thing to consider is the scientific value of finding an epistemically superior alternative assigned by the constructive empiricist as compared to our original anti-realist and realist, respectively. Let us grant that the constructive empiricist plausibly has reason to assign a higher scientific value to finding a radically distinct alternative than our original truthseeking anti-realist. After all, the constructive empiricist will find it more likely that the new

\footnotetext{
${ }^{23}$ I owe this version of the challenge to an anonymous referee.

${ }^{24}$ To be clear, I am not claiming that there is no sound argument for that conclusion; only that such an argument would need to appeal to considerations of a different sort than Stanford's argument (discussed in section 2).

${ }^{25}$ After all, all of the theories appealed to in such historical arguments have been shown to be empirically inadequate.
} 
theory is empirically adequate than our original anti-realist will find it to be true. By the same token, however, the realist has reason to assign an even higher scientific value to such an event than the constructive empiricist. After all, the realist does not value empirical adequacy any less than the constructive empiricist; rather, the realist also values truth beyond empirical adequacy. Since our realist thinks that this goal of achieving truth beyond empirical adequacy has plausibly been achieved when we succeed in finding a radically distinct, epistemically superior alternative, whereas the constructive empiricist only thinks that the new theory will plausibly be empirically adequate, the realist has greater reason to value the discovery of this new theory. So, in a similar way as before, the constructive empiricist occupies a middle ground between our realist and our original anti-realist with respect to the scientific value of finding radically distinct alternatives to current theories:

$$
\mathrm{SV}_{\mathrm{a}}(\mathrm{SUCCESS})<\mathrm{SV}_{\mathrm{c}}(\mathrm{SUCCESS})<\mathrm{SV}_{\mathrm{r}}(\mathrm{SUCCESS})
$$

Now, while this does show that moving from our original truth-seeking anti-realism to a form of constructive empiricism changes the assignments of probabilities and scientific value relevant to determining the expected scientific value of searching for radically distinct alternatives to current theories, we are still no closer to a sound argument that this expected scientific value is higher for the relevant anti-realist (which in this case is the constructive empiricist). After all, as we noted in section 3, such an argument would require that the scientific values of finding and not finding a radically distinct alternative are equal or lower for the realist as compared to the relevant anti-realist (which is now the constructive empiricist). But that condition is denied by the second double inequality above. Thus a Stanford-style argument from a difference in the probabilities of finding radically distinct alternatives to a corresponding difference in the expected scientific value of attempting to find such alternatives fails for much the same reason as before. ${ }^{26}$ To be clear, this is not to say that the constructive empiricist should place a lower (or even at most as high) expected scientific value on searching for radically distinct alternatives as compared to the realist, since the objection here (as before) shows only that a Stanford-style argument for the contrary conclusion is unsound - as opposed to establishing that this contrary conclusion is false.

\footnotetext{
${ }^{26}$ In addition, a valid Stanford-style argument would need to assume that the scientific value of failing to find a radically distinct, epistemically superior alternative is at least as high for the constructive empiricist as it is for the realist. Although I think it's doubtful that this condition holds (for much the same reasons as those appealed to in section 5), I lack the space here to discuss the issue thoroughly.
} 


\section{Conclusion}

Stanford presents an enticing argument that scientific realists can afford to be cavalier or even enthusiastic about theoretical conservatism in science, while anti-realists should view it with a great deal of suspicion. I have argued that this argument fails. Even if Stanford is right that realists should be more pessimistic that radically distinct, epistemically superior alternatives to currently accepted theories will be found, realists may still have just as much of a reason to search for such alternatives. In brief, this is because realists will view the possible outcomes of such a search (success and failure) as more scientifically valuable than their anti-realist opponents. ${ }^{27}$

\footnotetext{
${ }^{27}$ Many thanks to Sam Ruhmkorff, Huginn Thorsteinsson, three anonymous reviewers for this journal, the guest editor for this special issue (Adrian Currie), and the new editor-in-chief for SHPS (Darrell Rowbottom) for very helpful feedback on previous versions of this paper.
} 


\section{References}

Bird, A. 2007. What is Scientific Progress? Noûs 41: 64-89.

Bird, A. 2015. Scientific Progress. In P. Humphreys (ed.), Oxford Handbook in Philosophy of Science. Oxford: Oxford University Press.

Blackburn, S. 2002. Realism: Deconstructing the Debate. Ratio 15: 111-133.

Boyd, R. 1983. On the current status of the issue of scientific realism. Erkenntnis 19: 45-90.

Carnap, R. 1962. The Logical Foundations of Probability, 2nd ed. Chicago: University of Chicago Press.

Cartwright, N. 1983. How the Laws of Physics Lie. Oxford: Oxford University Press.

Chakravartty, A. 2007. A Metaphysics for Scientific Realism: Knowing the Unobservable. Cambridge: Cambridge University Press.

Chakravartty, A. 2008. What You Don't Know Can't Hurt You: Realism and the Unconceived. Philosophical Studies 137: 149-158.

Dawid, R. 2009. On the Conflicting Assessments of the Current Status of String Theory. Philosophy of Science 76: 984-96.

Dawid, R. 2013. String Theory and the Scientific Method. Cambridge: Cambridge University Press.

Dawid, R. 2017. Bayesian perspectives on the discovery of the Higgs particle. Synthese 194: 377-394.

Dawid, R., S. Hartmann, and J. Sprenger. 2015. The No Alternatives Argument. British Journal for the Philosophy of Science 66: 213-234.

Dawid, R., and S. Hartmann. Forthcoming. The no miracles argument without the base rate fallacy. Synthese, DOI: 10.1007/s11229-017-1408-x.

Dellsén, F. 2016. Scientific Progress: Knowledge versus Understanding. Studies in History and Philosophy of Science 56: 72-83.

Dellsén, F. 2017. Realism and the Absence of Rivals. Synthese 194: 2427-2446. 
Devitt, M. 2011: Are Unconceived Alternatives a Problem for Scientific Realism? Journal for General Philosophy of Science 42: 285-93.

Egg, M. 2016. Expanding Our Grasp: Causal Knowledge and the Problem of Unconceived Alternatives. British Journal for the Philosophy of Science 67: 115-141.

Fahrbach, L. 2011. Theory change and degrees of success. Philosophy of Science 78: 12831292.

Fahrbach, L. 2017. Scientific revolutions and the explosion of scientific evidence. Synthese 193: 5039-5072.

Fine, A. 1984. The Natural Ontological Attitude. In J. Leplin (ed.), Scientific realism, Berkeley: University of California Press, pp. 83-107.

Fine, A. 1991. Piecemeal Realism. Philosophical Studies 61: 79-96.

Forber, P. 2008. Forever Beyond Our Grasp? Biology and Philosophy 23: 135-41.

Frost-Arnold, G. 2014. Can the pessimistic induction be saved from semantic anti-realism about scientific theory? British Journal for the Philosophy of Science 65: 521-548.

Frost-Arnold, G. 2016. Should a historically motivated anti-realist be a Stanfordite? Synthese, DOI: $10.1007 / s 11229-016-1050-z$.

Godfrey-Smith, P. 2008. Recurrent Transient Underdetermination and the Glass Half Full. Philosophical Studies 137: 141-148.

Harker, D. 2013. How to Split a Theory: Defending Selective Realism and Convergence without Proximity. British Journal for the Philosophy of Science 64: 79-106.

Hacking, I. 1983. Representing and Intervening: Introductory Topics in the Philosophy of Natural Science. Cambridge: Cambridge University Press.

Henderson, L. 2017. The no miracles argument and the base rate fallacy. Synthese 194: 12951302.

Hertzberg, F. 2014. A note on "The no alternatives argument" by Richard Dawid, Stephan Hartman, and Jan Sprenger. European Journal for Philosophy of Science 4: 375-384.

Hesse, M. 1976. Truth and the Growth of Scientific Knowledge. PSA: Proceedings of the Biennial Meeting of the Philosophy of Science Association, vol. 2, pp. 261-280. 
Horwich, P. 1982. Probability and Evidence. Cambridge: Cambridge University Press.

Kitcher, P. 1993. The Advancement of Science: Science without Legend, Objectivity without Illusions. New York: Oxford University Press.

Kitcher, P. 2001. Science, Truth, and Democracy. Oxford: Oxford University Press.

Lange, M. 2002. Baseball, Pessimistic Inductions, and the Turnover Fallacy. Analysis 62: 28185.

Laudan, L. 1981. A confutation of convergent realism. Philosophy of Science 48: 19-49.

Lewis, P. 2001. Why the Pessimistic Induction is a Fallacy. Synthese 129: 371-80.

Lipton, P. 2000. Tracking Track Records. Proceedings of the Aristotelean Society 74: 179-205.

Lyons, T.D., and S. Clarke. 2002. Introduction: Scientific Realism and Commonsense. In T.D. Lyons and S. Clarke (eds.), Recent Trends in Philosophy of Science, Dordrecht: Kluwer, pp. ix-xxiii.

Magnus, P. D., and C. Callender. 2004. Realist ennui and the base-rate fallacy. Philosophy of Science 71: 320-338.

Maher, P. 1990. Why Scientists Gather Evidence. British Journal for the Philosophy of Science 41: 103-119.

Malinas, G., and J. Bigelow. 2016. Simpson's Paradox, in E.N. Zalta (ed.), The Stanford Encyclopedia of Philosophy (Fall 2016 Edition), URL = <https://plato.stanford.edu/archives/fall2016/entries/paradox-simpson/>.

Musgrave, A. 1988. The Ultimate Argument for Scientific Realism. In R. Nola (ed.), Relativism and Realism in Science, Dordrecht and Boston: Kluwer Academic Publishers, pp. 229252.

Peters, D. 2014. What Elements of Successful Scientific Theories Are the Correct Targets for "Selective" Scientific Realism? Philosophy of Science 81: 377-397.

Poincaré, H. 1952/1905. Science and Hypothesis. New York: Dover. Republication of the first English translation, published by Walter Scott Publishing, London.

Potochnik, A. 2015. The diverse aims of science. Studies in History and Philosophy of Science 53: 71-80. 
Psillos, S. 1999. Scientific realism: How science tracks truth. New York: Routledge.

Putnam, H. 1975. Mathematics, matter and method. Cambridge: Cambridge University Press.

Putnam, H. 1978. Meaning and the Moral Sciences. London: Routledge.

Roush, S. 2009. Optimism about the pessimistic induction. In P. D. Magnus \& M. Busch (eds.), New waves in philosophy of science, New York: Palgrave MacMillan, pp. 29-58.

Rowbottom, D. P. 2011. The instrumentalist's new clothes. Philosophy of Science 78: 12001211.

Ruhmkorff, S. 2011. Difficulties for the Problem of Unconceived Alternatives. Philosophy of Science $78:$ 875-886.

Ruhmkorff, S. 2015. Unconceived alternatives and the cathedral problem. Synthese, DOI: 10.1007/s11229-015-0947-2.

Saatsi, J. 2015. Historical inductions, old and new. Synthese, DOI: 10.1007/s11229-015-08555.

Saatsi, J. 2016. What is theoretical progress of science? Synthese, DOI: 10.1007/s11229-0161118-9.

Saatsi, J. 2017. Replacing recipe realism. Synthese 194: 3233-3244.

Smart, J.J.C. 1963. Philosophy and Scientific Realism, London: Routledge \& Kegan Paul.

Sprenger, J. 2016. The probabilistic no miracles argument. European Journal for Philosophy of Science 6: 173-189.

Stanford, P.K. 2000. An Antirealist Explanation of the Success of Science. Philosophy of Science 67: 266-284.

Stanford, P.K. 2006. Exceeding Our Grasp: Science, History, and the Problem of Unconceived Alternatives. Oxford: Oxford University Press.

Stanford, P.K. 2015a. "Atoms Exist" Is Probably True, and Other Facts That Should Not Comfort Scientific Realists. Journal of Philosophy 112: 397-416.

Stanford, P.K. 2015b. Catastrophism, Uniformitarianism, and a Scientific Realism Debate That Makes a Difference. Philosophy of Science 82: 867-878. 
Stanford, P.K. 2015c. Unconceived alternatives and conservatism in science: the impact of professionalization, peer-review, and Big Science. Synthese, DOI: 10.1007/s11229015-0856-4.

van Fraassen, B.C. 1980. The Scientific Image. Oxford: Clarendon Press.

van Fraassen, B.C. 2001. Constructive empiricism now. Philosophical Studies 106: 151-170.

Worrall, J. 1989. Structural realism: The best of both worlds. Dialectica, 43, 99-124.

Worrall, J. 1994. How to remain (reasonably) optimistic: Scientific realism and the “Luminiferous Ether". In R. M. Burian, D. Hull. M. Forbes (eds.) PSA 1994: Proceedings of the 1994 Biennial Meeting of the Philosophy of Science Association, volume 1, pp 334-342.

Wray, K.B. 2015. Pessimistic Inductions: Four Varieties. International Studies in the Philosophy of Science 29: 61-73. 